\title{
The better can be the enemy of the good. The timing of LV venting during complex open-heart surgery revisited.
}

Francesco Ferraro ${ }^{1}$, Herve Schlotterbeck ${ }^{1}$, Patrick Scharpf $^{1}$, Stefanos Demertzis ${ }^{1}$, and Thomas Theologou ${ }^{1}$

${ }^{1}$ Cardiocentro Ticino

January 27, 2022

\begin{abstract}
We report a patient that underwent a redo complex AVR. In the context of severe AR and dilated LV, we experienced that it is safer to start the LV venting after aortic cross clamping. NIRS in this setting can be a useful tool to prevent potential severe neurological damage.
\end{abstract}

The better can be the enemy of the good. The timing of LV venting during complex open-heart surgery revisited.

Ferraro $\mathbf{F}^{1}$, Schlotterbeck $\mathbf{H}^{2,3}$, Scharpf $\mathbf{P}^{2,3}$, Demertzis $\mathbf{S}^{1,3}$, Theologou $\mathrm{T}^{1,3}$

${ }^{1}$ Department of Cardiac Surgery Cardiocentro Ticino via Tesserete 48, 6900 Lugano Switzerland.

${ }^{2}$ Department of Cardiac Anaesthesia Cardiocentro Ticino via Tesserete 48, 6900 Lugano Switzerland.

${ }^{3}$ University of the Italian Switzerland (USI), Faculty of Biomedical Sciences, Via Giuseppe Buffi 13, 6900 Lugano Switzerland.

ABSTRACT: We report a young female patient with a complex cardiac surgical history that underwent a redo complex aortic valve replacement. In the context of severe AR and dilated LV, we experienced that it is safer to start the LV venting after aortic cross clamping. In this setting NIRS can be, in this particular context, a useful monitoring tool to prevent potential severe neurological damage.

"Written informed consent was obtained from the patient to publish this report in accordance with the journal's patient consent policy".

IRB approval: N/A

Consent statement: N/A

Clinical Trial: N/A

Word count: 1177

Corresponding author:

Dr. Thomas Theologou, FRCSC-Th

Staff Cardiac Surgeon

Cardiocentro Ticino 
Via Tesserete 48, 6900-Lugano Switzerland

Tel: +41918055139

Fax: +41918055148

thomas.theologou @gmail.com

\section{CASE REPORT}

A 66 years old female admitted to our department for a redo aortic valve replacement. A year before, she underwent successful emergency surgery for an acute type A aortic dissection with reconstruction of the aortic root, resuspension of the aortic valve commissures, replacement of the ascending aorta and proximal hemi-arch. One month later, she underwent a percutaneous endovascular insertion of a stented graft in the thoracic descending aorta, which was critically compressed by the increasing diameter of the false lumen at the residual Type B dissection. She developed progressively severe AR with LV dilatation and therefore she underwent aortic valve replacement with a Trifecta? $23 \mathrm{~mm}$ bioprosthesis 9 months after the initial procedure. For cerebral perfusion monitoring a NIRS device was placed on the patient before surgery.

After initiating extracorporeal perfusion and to avoid distension of the dilated LV a venting cannula was inserted into the LV through the RSPV. LV venting was initiated with a flow rate of $400 \mathrm{ml} / \mathrm{min}$. The anesthesiologists immediately reported a bilateral significant drop of the brain saturation as evidenced by NIRS device (Fig. 1). After exclusion of the usual causes of cerebral saturation drop, we interrupted the LV venting, as it was the last surgical step done. The values of the cerebral $\mathrm{O}_{2}$ saturations immediately started improving, returning at the baseline level (Fig. 2). The hemodynamic situation of the patient was stable during all this time period (blood pressure, heart rate, ECC-flow and venous return).

To perform the operation safely, LV venting was then reduced to a minimum until aortic cross-clamping. Thereafter it was increased again. The operation could be completed without further NIRS saturation drop incidents. During the first post-operative sedation break, the patient was neurologically intact. The post-operative evolution was without complications.

\section{DISCUSSION}

In complex aortic surgery especially in repairing of dissected aortas or in complex situations where cerebral circulation could be compromised, for example in redo aortic arch surgery, monitoring of the brain perfusion/oxygenation is of paramount importance. New modalities like NIRS that monitor oxygen saturation of the brain $\left(\mathrm{rSO}_{2}\right)$ as a surrogate, can give an optimal peri-operative assessment. The NIRS device monitors in real time the cortical regional cerebral oxygenation and gives us an instant information about cerebral perfusion/oxygenation adequacy as well as the incidence and time course of cerebral hypoxia. At the same time, it may help to identify the causes and find methods of preventing and managing cerebral hypoperfusion and hypoxia during cardiac surgery [1].

In our case, the observed NIRS dropped dramatically after the LV venting started. That was probably due to the stealing of a significant amount of anterograde cardiac flow by the LV venting suction in the context of a severe AR. As a result, the brain perfusion was compromised and the brain $\mathrm{rSO} 2$ dropped. By reducing the LV vent drainage (until aortic cross-clamping), we managed to perform the rest of the operation without difficulty.

The use of a LV venting prevents distension of the left ventricle in so avoiding sub-endocardial ischemia to the muscle from excessive stretching. Vents can be placed in the aortic root, left atrium or left ventricle via the left superior pulmonary vein, left ventricular apex, or pulmonary artery. It was originally recommended to insert the LV venting cannula just after applying the cross clamp in the aorta to minimise introduction of air into the left heart and subsequent systemic air embolism [2]. Alternatively, nowadays we are using the RSPV cannulation as a LV venting. To minimize risk of air insertion during cannulation the heart is usually allowed to fill before vent insertion and clamped immediately after connection to the venting cannula of the CPB. This technique, however, can bear complications [3]. This is most likely to occur at the time of 
insertion or removal of the venting catheter from the RSVP. Finally, errors in function of the suction (positive pressure in reservoir, misdirection of tubing into roller pump head, reversal of roller pump) may cause air to be pumped into the ventricle. A number of cardiac surgeons to avoid these potential complications refrain from the use of an LV venting and use only a small transvalvular cardiotomy suction while performing valve replacements [4].

We suggest keeping this rare complication of LV venting via the RSVP in mind, in the context of severe AR and dilated LV. In doubt, it is safer to start it after aortic cross clamping. NIRS can be, in this particular context, a useful monitoring tool to prevent potential severe neurological damage.

\section{Authors 'contributions :}

Concept/design: SD, TT

Data analysis/interpretation: TT, HS, PS

Drafting article: HS, PS, TT, FF

Critical revision of article: TT, SD

Approval of article: SD, TT

Data collection: FF

\section{DISCLOSURES: All the authors report no conflict of interest on this study REFERENCES}

1. Heringlake M, Garbers C, Kabler JH, Anderson I, Heinze H, Schon J, Berger KU, Dibbelt L, Sievers HH, Hanke T. Preoperative cerebral oxygen saturation and clinical outcomes in cardiac surgery. Anaesthesiology. 2011; 114(1):58-69. doi: 10.1097/ALN.0b013e3181fef34e

2. Buckberg GD. The importance of venting the left ventricle [Editorial]. Ann Thorac Surg 1975; 20:488-490.

3. Utley JR, Stephens DB. Venting during cardiopulmonary bypass. In: Utley JR, ed. Pathophysiology and techniques of cardiopulmonary bypass. Baltimore: Williams \& Wilkins, 1983:115-127.

4. Arom KV, Vinas JF, Fewel JE, et al. Is a left ventricular vent necessary during cardiopulmonary bypass? Ann Thorac Surg 1977; 24:566-573.

\section{Hosted file}

Fig 1.docx available at https://authorea.com/users/457608/articles/554325-the-better-canbe-the-enemy-of-the-good-the-timing-of-lv-venting-during-complex-open-heart-surgeryrevisited

\section{Hosted file}

Fig 2.docx available at https://authorea.com/users/457608/articles/554325-the-better-canbe-the-enemy-of-the-good-the-timing-of-lv-venting-during-complex-open-heart-surgeryrevisited 